\title{
Colorado's Ryan White screening, brief intervention, and referral to treatment collaborative project to address substance use in HIV/AIDS case management and health-care settings
}

\author{
Leigh Fischer
}

From International Network on Brief Interventions for Alcohol Problems (INEBRIA) Meeting 2011

Boston, MA, USA. 21-23 September 2011

This presentation discusses screening, brief intervention, and referral to treatment (SBIRT) for substance use within HIV/AIDS treatment and care programs and lessons learned from Colorado's Ryan White SBIRT collaborative project. Evidence demonstrates that SBIRT in primary care settings is effective in changing behavior and preventing adverse outcomes attributable to alcohol and other drugs. Studies also show people living with HIV are more likely to experience substance abuse problems than the general population, and early detection offsets the negative ramifications, including poor treatment adherence. Despite the linkage between substance use and HIV, screening and brief intervention protocols have not been readily adopted in HIV/AIDS services in the United States. In order to introduce SBIRT procedures tailored for HIV/AIDS care, Colorado implemented a collaboration between the state's SBIRT initiative and its Ryan White Part B HIV treatment and care program. Of 2500 patients screened, 31\% received a brief intervention for risky alcohol, tobacco, or drug use, and $23 \%$ were referred for therapy or specialized treatment. Program evaluation findings gathered from focus groups and patient and provider surveys indicate that SBIRT can be successfully integrated into HIV treatment and care to address risky substance use. We explore the barriers to implementing SBIRT in HIV care and identify the administrative and policy considerations necessary for effective implementation. Recommendations are made for standardizing SBIRT in HIV care (applying a systematic

Peer Assistance Services, Screening, Brief Intervention, and Referral to Treatment (SBIRT) Colorado, Denver, CO, USA approach to screening; training providers to conduct brief interventions; establishing a referral network; and integrating SBIRT with adherence and retention efforts).

Published: 9 October 2012

\section{doi:10.1186/1940-0640-7-S1-A73}

Cite this article as: Fischer: Colorado's Ryan White screening, brief intervention, and referral to treatment collaborative project to address substance use in HIV/AIDS case management and health-care settings. Addiction Science \& Clinical Practice 2012 7(Suppl 1):A73.

Submit your next manuscript to BioMed Central and take full advantage of:

- Convenient online submission

- Thorough peer review

- No space constraints or color figure charges

- Immediate publication on acceptance

- Inclusion in PubMed, CAS, Scopus and Google Scholar

- Research which is freely available for redistribution 